\title{
The E-Customer: \\ Customer Relationship And Retention
}

Jaymeen Shah, (E-mail: js62@business.txstate.edu), Texas State University, San Marcos

Vivek Shah, (E-mail: vs01@business.txstate.edu), Texas State University, San Marcos

\begin{abstract}
E-commerce is currently being used by organizations to increase their market share while retaining customer loyalty. This paper discusses ways that organizations can use to attract new customers and retain existing customers to attain sustained profit growth. Data warehousing, data mining, and customer relationship and retention approaches that can be used for assisting organizations achieve these goals are discussed.
\end{abstract}

\section{Introduction}

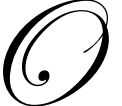

rganizations are facing difficulties in retaining customers in today's competitive market. Whether they are classic brick-and-mortar businesses such as Ford or burgeoning dot.coms such as Travelocity, many are fighting to stay afloat in current business environment that is different from the past environment due to emerging sales channels, rapid introduction of improved and innovative products, and increased global competition. Emergence of business-to-consumer e-commerce via the Internet has provided consumers with many more choices than before. With thousands of websites just a mouse-click away, customers can easily obtain comparative information about these choices in a very short time without leaving their homes or offices. This ability of customers to collect and compare information about large number of product and vendor alternatives have given them significant leverage in being able to purchase products at the best available price. Intelligent agents based systems are available that can help buyers in discovering the best prices and terms available for products they want to purchase from vendors located in different regions in just a few minutes (Gunasekaran et al., 2002).

The ubiquity of the Internet, availability of easy to use technology, and significant development in ebusiness models and technologies has redefined customer expectations. Customers now expect organizations to provide rapid service that is available round-the-clock -- and at a lower cost. They expect organizations to not only meet their specific needs, but also to anticipate what those needs will be in the future. For example, due to developments in e-business technologies and easy access to the Internet, consumers can pay bills, inquire about their bank accounts, purchase airline tickets, purchase books, and buy their groceries online using computers and without having to leave their living rooms (Hall, 2001). Now many consumers use these types of services, and they expect organizations to provide these services. The worldwide value of goods traded over the Internet - both business-tobusiness and business-to-consumer was approximately $\$ 15$ billion in 1999, and was expected to grow to over $\$ 200$ billion by the end of year 2002 (Morphett, 1999; Feraud, 2000).

Technology is changing faster than customers, customers are changing faster than organizations and organizations are changing faster than the people who run them (McKeown, 2001). In addressing this challenge of coping with changing customer characteristics and needs, many organizations have discovered that the key to achieving customer loyalty is the ability to harness technology to both, enhance productivity, and to attract and retain customers (Hall, 2001). It has become inevitable for organizations to develop and merge e-business strategies with their existing strategies based on physical stores due to the significant increase in the number of e-business transactions and dollar amount spent by consumers on online purchases. The availability of this new channel for sales, service, and advertisement is reshaping the future competition as it is allowing new competitors to enter markets that were difficult to penetrate before. To survive and grow in this competitive environment, organizations have realized that it is necessary to reengineer their business strategies and processes, and invest in technology 
infrastructure to support e-business activities. An InternetWeek's survey of 1,000 IT and corporate managers revealed that two-thirds of the managers indicated that their organization had to adopt and invest in e-business projects due to competitive pressures (Violino, 2001). This survey result clearly implies that top management is aware of the importance of e-business activities for their organization's survival and future growth. The purpose of this paper is to discuss tools and approaches that organizations can adopt and use to attract new customers and retain existing customers in an e-business environment.

The remainder of the paper is comprised of the following six sections: (1) Emergence of e-business, (2) Transforming business practices, (3) Information explosion, (4) Customer relationship management, (5) Customer retention, and (6) Summary. The second and third sections provide discussion about the growth of the Internet and e-business, and its effects on the traditional business practices. The fourth section discusses the relevance of collecting and organizing customer and business data for competitiveness. The next two sections focus on the issues of customer relationships and retention. Finally, a brief review about the effects of e-business and the Internet is presented in the Summary section.

\section{Emergence of E-Business}

Emergence of e-business and the Internet has created significant opportunities for organizations, although not without many challenges. It has increased the use of IT in an organization's business strategy, and has profoundly changed the way in which business is conducted.

E-business is not just a single technology but a combination of technologies, applications, processes, business strategies, and practices necessary to do business electronically (Taylor and Bregg, 1995). The widespread availability of the infrastructure required for e-business and easy to use web browsers have allowed retailers and service providers to reach potentially millions of customers worldwide. More choices, lower prices, and the creation of entirely new product categories are among the changes being brought about by e-business in the market place. Growing number of organizations are conducting increasing number of electronic transactions as more of their customers and suppliers now have the technology required for conducting electronic transactions (Gunasekaran et al., 2002). Consumers have also become sophisticated in their use of the Internet to research and purchase products online, which has made organization's website important as it can attract new customers.

Business-to-consumer and business-to-business e-business has required businesses to streamline business processes to improve their efficiency and integration (Laudon and Laudon, 1997). Organizations have realized that to be profitable and to ensure their growth, it is essential for them to exploit e-business technologies to link and integrate their business processes with their business partners and customers as it enables them to reduce costs and react quickly to the changes in the competitive pressures and customers' needs (Gunasekaran et al., 2002; Turban et al., 2000; Block and Segev, 1996). Historically, only large organizations could establish supplier/vendor networks using EDI or other proprietary technology (Harreld et al., 2002; Hill, 2002; Rooney, 2002). Now, the costeffectiveness and easy availability of the Internet and related technologies have enabled small and mid-size organizations to reap the rewards of supplier connection (Harreld et al., 2002; Rooney, 2002). To take advantage of e-business opportunities, it may be necessary for businesses to transform traditional business practices.

\section{Transforming Business Practices}

Although, successful e-business strategy implementation requires use of new technologies, it emphasizes more on improved relationships with customers and suppliers. It involves more than development and deployment of websites to facilitate transactions with customers/suppliers, it also entails managing important customer/supplier relationships that lead to and arise from these transactions (VanderAalst, 1999). As with any strategic initiative undertaken, e-business technology is an enabler. Selection and deployment of appropriate e-business technology is important to ensure successful e-business with business partners and consumers. E-business technology selected must allow easy and effective integration with business partners' systems. It should also enable consumers to easily complete business transactions. 
Evolution of e-business has generated profound changes in organizations' business models, with increasing emphasis being placed on innovation and the concept of service. Businesses have changed how they interact with their customers and how they treat them - current practice emphasizes on personalization and service. The focus has changed from "Get the customer into the store/to the web-site" through mass marketing and banner ads to "Keep the good customer coming-back" (Dyche, 2000). Due to the nature of the medium, Internet merchants have a much harder time when it comes to fostering consumer trust than their brick-and-mortar counter parts. Security and trust are the most cited reasons by large number of consumers for not shopping online (Laudon \& Traver, 2002). Consumers grant their trust to businesses that have a close physical presence; buildings, facilities, and people to talk to. On the Internet, these familiar elements are missing. Many consumers begin their buying process on the Internet, which generally involve research about a product. However after completing their research, they tend to complete their purchase process at a brick-and-mortar store.

E-business technologies are eliminating activities that historically have been carried out by the relevant participants in both the customer and supplier organizations. Such changes pose an immense challenge to the role of the intermediaries, both people and organizations, involved in managing the inter-organizational interactions. For example, a manufacturer can by-pass distributors and retailers, and sell directly to the end-customer. This may require businesses to reevaluate strategic relationships with its business partners. E-business is changing the competitive environment in a number of ways, by reshaping buyer-supplier relationships, improving core business processes, providing electronic intermediation, and reaching new segments and markets (McIvor et al., 2000). Although e-business has made disintermediation a reality, increased collaboration and sharing of information between business partners has also become a norm. Business partners share customer and business data and intelligence across the supply chain to maximize competitive advantage and agility required to prosper in dynamic business environment.

\section{Information Explosion}

Businesses have become fascinated with collecting data about their customers on real-time basis, irrespective of where customers are or what time they initiated and completed purchase transactions. Customers' research and purchase transactions result in a lot of data, especially when it is accumulated over a month or over several years. This data about customers provide tremendous amount of potentially useful information that businesses and their business partners can use to formulate successful business strategies to attract new customers and retain existing customers.

It is easy to collect large amount of customer data from point-of-sale terminals at a brick-and-mortar store and from organization's websites. However to ensure that these data is of value to the organization, it is important to properly store, organize, and analyze customer data to allow decision-makers to obtain a complete profile about current and potential customers. This will enable organizations to answer questions about customers' purchase habits, buying power, interests, etc. The rationale for developing the capability to answer such questions is that the more an organization knows about its current and potential customers, the more it is likely to be able to attract them to come back and buy more by offering products that are of value to them.

Data warehousing technologies have emerged as a tool for storing and managing large amount of customer and business data collected by businesses. It has been used by organizations to clean and consolidate business and customer data to ensure that it continues to serve business needs. Clean and consistent data is a business-critical issue, as poor quality and inconsistent data can break the databases and data warehouses that drive e-business (Paulson, 2000). Data warehousing tools should be integrated with data-cleansing tools, and possess extraction, transformation, and transportation functionalities. These capabilities reduce time required for transferring, cleaning, and preparing data for mining.

Data-mining tools are used in conjunction with well designed data-warehouses to extract hidden business/customer knowledge from the data collected, which can be used by decision makers within an organization to support their business decisions. Data mining has been defined as the process of selecting, exploring, and analyzing, by automatic or semi-automatic means, large amounts of data to discover meaningful patterns and rules 
for business advantage (Berry and Linoff, 2000; SAS Institute, 2000). It is a useful tool for identifying emerging business trends, which provides organizations with the ability to react to these changes in a proactive and timely manner. It should be noted that irrespective of whether predictive modeling, decision tree, or neural network based methods are used within a data mining tool, it is unlikely to produce actionable business results without availability of clean consolidated data from the data warehouse. Thus the structure of the data warehouse and capability of the data warehouse tool is of significant importance for effectively analyzing business/customer data using a data mining tool.

Popularity of the Web as a medium for conducting business and disseminating product and organization information has led to the emergence of the concept of e-mining. Mena (1999) defines e-mining as the iterative process of analyzing the patterns of an organization's online transactions and extracting knowledge about who is buying what, when, and, most importantly, why from its web site. It deals with extracting previously hidden, actionable intelligence from organization's web site interactions.

Properly designed data warehouses along with appropriate data mining tools enable organizations to answer questions such as the following: How much revenue was generated by a banner advertisement? Who are their customers? What percentages of online customers abandon their market baskets? Which customers bought a particular product online? What are their needs, and how they will change in the future? What can they do to retain their customers? Answers to such questions can lead to better customer relationship and marketing strategies.

Analysis of customer data collected in the data warehouse on a regular basis can aid organizations in identifying and anticipating changes in their customers' needs. Availability of such information enables management to develop strategies required to deal with these anticipated changes in customer needs before their competitors can react to these changes. Rapid actions can mean nothing less than competitive advantage, which can provide the organization with the ability to retain current customers and attract new customers. Customer retention is imperative to be successful in hyper-competitive global markets as organizations incur significant customer acquisition costs. It is estimated that it costs organizations five times more to acquire a new customer than to retain an existing customer (Weinstein, 2001). To increase customer retention rate, in addition to using data mining and other technologies, it is necessary for organizations to train and retain loyal employees. Frontline employees provide information that can be used to develop strategies to enhance customer relationships as they interact directly with customers. Thus, focus on retaining loyal employees is also critical for improving customer relationships and building a base of loyal and profitable customers (Finnie and Randall, 2002).

\section{Customer Relationship Management}

E-business and the Internet revolution have augmented the number of channels that a customer can use to purchase a product or to interact with a business. Different customers may leverage different channels and to a different extent for different purpose. This has made it difficult for organizations to understand what their current and potential customers are doing. To fully understand customer behavior businesses need to consolidate and analyze customer behavior across the various channels. This information can be used by organizations for planning and implementing their e-business initiatives.

Customer relationship management (CRM) tools use integrated customer data combined with other relevant business information to better understand customers' behavior and attitudes, and their effects on current and future demands for specific products and services. Enhanced understanding of customer needs enable organizations to deliver timely, accurate, and customized products and services to their customers, resulting in satisfied customers. It allows organizations to differentiate customers according to their needs and value, and properly match customer needs with their products. Better understanding of customers allow organizations and its salespeople to develop and launch smart campaigns, which can result in increased sales by retaining existing customers and attracting new customers.

CRM suites have the capability to track and analyze customers' web activities and incorporate it into the ebusiness model being used to develop a better understanding about existing and potential customers' behavior and 
needs. It should be noted that even the most effective CRM tool will only provide results that are as good as the data that it is provided from the data warehouse. Thus, proper implementation of data warehouse is of prime importance.

Brief discussion about some of the initiatives that have been undertaken by organizations to support and enhance customer relationships to retain existing customers and attract new customers is provided below.

\section{Sales Force Automation}

Sales Force Automation (SFA) tools access data contained in data warehouse to generate useful information that can be used by salespeople responsible for different types of customers to develop new and enhance existing customer relationships. SFA tools allow salespeople to access customer profiles, interactively update contact information, and review and analyze actual customer sales data (Dyche, 2000). This information assists salespeople in forecasting future sales, and in developing the most appropriate marketing and customer relationship initiatives.

Salespeople need complete information about their market segments to develop effective sales strategies for selling products and services to customers in different market segments and to maintain excellent customer relationships. It may not be possible for salespeople to visualize and understand the complete business scenario, if the data provided to them represents a simple vertical snapshot that is specific to a line of business or customer segment. This could result in flawed sales strategies and misinformed customer contacts that could adversely affect sales and customer relationships. To boost usefulness and performance of SFA tools it is essential that they are integrated with a well designed data warehouse. Many SFA projects have failed due to lack of data integration, resulting in missing or inaccurate information (Baron, 2000).

\section{Campaign Management}

Combining information about past sales history and customer preferences with the new product development process can lead to the development of products that appeal to customers. Campaign management involves a closed loop process in which results of past campaigns are analyzed and fed as an input for developing future sales campaigns and promotions, which leads to formulation of more effective sales campaigns. Campaign management tools have been available since the mid-'90s, but rapid growth in their adoption and use over the past few years has brought new vendors and offerings into the mix. The average advertiser, agency, or publisher now has dozens of options to choose from -- something that's both a blessing and a curse (Bannon, 2002).

\section{Customer Interaction Personalization}

E-businesses and brick-and-mortar stores with web sites collect and analyze clickstream data. A clickstream is a collection of data representing the actual navigation path used by a user when visiting a website. Clickstream data can be stored in the data warehouse. It can be integrated with other business/customer data stored in the data warehouse and analyzed (mined) to assist an organization answer questions related to how customers access its website, what do they do when they browse and navigate through the website, which visitors abandon their online shopping cart without completing the purchase, etc. In addition, organizations such as Amazon.com have used clickstream data to personalize communication with customers. Collaborative filtering technologies and personalized portals are also used by organizations to personalize communication with customers.

Collaborative filtering technologies are used for customizing web messages to individual shoppers. It is used to dynamically launch personalized messages in response to a customer's click. Many organizations such as Delta Airlines have adopted personalized e-mail messages as an advertising media because of its speed, flexibility, cost-effectiveness, and ease of personalizing e-mail messages (Dyche, 2000). Organizations like Dell are creating personalized portals for customers, enabling advanced target marketing and custom communications with customers. These technologies enable organizations to provide right information and right amount of it to the customer at the right point in time, which is vital for enhancing customer relationships. 


\section{Customer Privacy}

Privacy and security concerns have affected the growth of business-to-consumer e-business (Bellman et al., 1999). Many consumers are reluctant to use the Internet for purchasing products as they are not sure about many critical issues such as the following: (1) whether their personal information required to be transmitted to the web site over the Internet will be secure or not, (2) how will the organization handle their personal information, (3) who will have access to their personal information, both inside and outside the organization, and (4) who is responsible for restitution in case of loss or fraud.

Organizations may be able to better exploit business-to-consumer e-business opportunities by developing customer-oriented privacy policies that are clearly presented on organization's websites. It is necessary for them to explain to customers how the stated privacy policies are actually implemented. This is particularly important for new organizations that intend to conduct business-to-consumer e-business. Organizations need to explicitly state the purpose of collecting personal information, especially if it is being used for providing better service to the customers. This will facilitate customer's understanding regarding why an organization is requesting particular personal information, which may alleviate customer's anxiety about divulging personal information over the Web. Wang et al.'s (2000) study showed that 96 percent of customers need organization's websites to explain in detail how their personal information revealed during the purchase process will be used by the organization.

It is imperative for organizations involved in e-business to assure customers that their private information will be protected, and it will not be misused or shared with any other businesses or individuals. Organizations need to develop contingency plans to deal with security breaches that could jeopardize customer information (Lejeune, 2001), and have clearly stated policies about how customer reparation will be handled when a significant loss or fraud occurs. Implementation of such policies and procedures will enhance customers' confidence and trust in dealing with the organization, which is vital for developing and maintaining long-term customer relationships. Trust is one of the main concerns of online customers who are more likely to revisit and buy from trusted web sites, which will translate in to higher profits for the organization (Lais, 2002). Organizations should also invest in technologies that support secure e-business transactions to safeguard customer data.

\section{Customer Retention}

Experience has revealed that it is not easy for businesses to harness the power of the Internet for growth as its use has made it easy for consumers and businesses to be well informed about different vendors' product/service offerings, and take their business to a competitor. Thus, retention of existing customers, particularly profitable customers, has become more important for an organization to achieve long-term customer value. Some of the factors that affect customer retention include customer's overall satisfaction, future expectation and use, website quality, and customer privacy (refer to previous section). Organizations need to closely monitor these factors to retain current customers and attract new customers. A brief discussion regarding the first three factors is provided below.

\section{Overall Satisfaction}

One of the key elements that affect customer retention is customers' overall satisfaction with organization's product(s)/service(s) (Kotler, 2000; Strauss et al., 2001). Customer satisfaction is affected by the value proposition offered to customers, which in turn depends upon the combination of product quality, service, price, innovation, and intangibles offered by the organization (Weinstein, 2001). Satisfied customers tend to stay longer with the organization, are less price sensitive, and are more likely to recommend organization's products/services to potential customers (Kotler, 2000; Ralston, 1996). Keaveney's (1995) research on customer switching behavior revealed that about 70 percent of the customers switched due to dissatisfaction caused by service-oriented factors, and only 17 percent of the customers defected because of pricing issues. Proper customer relationship management usually ensures higher level of customer satisfaction, which will assist organizations in retaining existing customers and attracting new customers. 


\section{Expected Future Use}

Lemon et al. (2002) conducted a research study to evaluate the effect of future expectations and use on customers' decision to keep/drop a service. Results of the study revealed that customers factor expectations about future use, in addition to their overall satisfaction with the product/service when deciding whether to continue using a product/service. It was found that customers are more likely to continue using organization's product/service when they anticipated high expected future use for the product/service. Results suggested that the expected future use of product/service mediates the effect of overall satisfaction on the keep/drop decision, which indicates that high expectations of future use may override low satisfaction and low expectations of future use may override higher levels of satisfaction with the product/service. These results imply that organizations need to monitor customers' expectation of future use for their products/services, and understand the antecedents that affect the expected future use of their products/services.

Analysis of customer/business data using data mining tools and input from salespeople dealing directly with customers will reveal important trends regarding changes in customers' future needs and expectations. This information can be used by organizations to evolve their existing products/services or develop new products/services to satisfy customers' evolving needs and expectations, increasing the likelihood of retaining existing customers and attracting new customers. Failure to incorporate the forward-looking characteristics of customers' needs and expectations in addition to the overall satisfaction element could result in organization developing inaccurate customer retention strategies.

Customers continue to update their existing perceptions about a product or service based on the new experience gained by using a product/service and their future forecast about the anticipated use of the product/service. Active changes in customers' perceptions about products/services and needs make it necessary for organizations to develop dynamic customer relationship management strategies.

\section{Website}

Effective website is a key element for attracting and retaining customers, especially e-customers. Organizations loose millions of dollars in potential sales due to inefficient and ineffective websites as they drive away almost $70 \%$ of the customers that visit them, and poor website usability is one of the main reason for this loss (Lais, 2002). Some of the suggestions provided by practitioners and academicians for designing websites that will enhance customers' experience of using organization's websites are presented in Table 1. Higher website usage by customers is a good indicator of a commercial website's success (Liu and Arnett, 2000), which can positively affect organization's profitability.

Table 1 - Suggestions for enhanced website design to improve usage experience

(Chen et al., 2002; Lais, 2002; Lin and Lu, 2000)

In addition to the quality of information presented on the organization's website, its response time also significantly affects website usage. Response time is an important factor to be considered when designing the website as a shorter response time leads to a smoother interaction between the user and system (web site), which results in a higher perceived ease of use of the website by the user (Eighmey, 1997). Higher perceived ease of use of the website has a positive effect on the user's intentions to revisit and reuse the website (Lin and Lu, 2000), which is critical for customer retention. Thus, well designed websites will enhance organization's ability to attract new customers and retain existing customers, Provide features for easy navigation and use of the website

Enable easy and convenient checkout

Use simple language, and avoid jargon

Display full product cost as soon as possible, and additional information such as units in stock

Cross-reference products to enhance product search and selection

Provide good search engine and a search box on each page

Provide help facility to assist users to search for information or solve common problems

Provide toll-free number on the website to place phone orders and get technical support

Present clear images, with zoom in ability, that show product features important to buyers

Provide interactivity and user control for such activities as product configuration and search

Explain clearly reasons for collecting personal information

Allow shopper to select opt-in/opt-out to give more control over data sharing

Provide detailed customer service information, clearly stated return policy, and contact/return address

Provide up-to-date, accurate, and rich information about products

Provide additional product information that can assist in decision making and to predict satisfaction with the product

Efficient website that ensures short response time

Thoroughly tested website to eliminate errors and downtime 


\section{Summary}

E-business has evolved from a concept to reality. Millions of e-transactions are executed daily around the world using the Internet/Intranets. Consumers and businesses have become adept at using this channel for product research and consummating business transactions. It is critical for businesses to understand and exploit this channel for survival and growth.

To exploit e-business positively for growth, it is important for businesses to understand it and use tools that can assist in coping with the evolution brought about by the Internet. Customer relationship and retention have become more important than ever, and they should be the prime focus of the organization. Some of the concepts and tools that businesses can use to enhance customer relationship and retention include data warehousing and data mining, customer relationship and campaign management, and personalization of customer interactions via the use of collaboration technologies and personal portals. Developing well-designed websites, and ensuring customer privacy and trust are also critical for customer retention.

Proactive management of customer relationships has become even more important with the emergence of the Internet and e-business, as it has allowed customers to research competing products/services without expending too much time, effort, or money. Internet has made the customer defection problem more acute as it has increased customer power and competition, and made it easier for them to defect with just a few clicks of a mouse (Peppard, 2000; Lejeune, 2001). Organizations have to develop strategies aimed at increasing customer loyalty to retain loyal and profitable customers. This is important for organization's profitability and growth.

Organizations can attempt to increase customer loyalty by developing long-term relationships with customers. Internet and wireless channels of communication should be exploited by organizations to enhance customer relationship. Internet has made it easier and cost-effective for organizations to personalize communication with customers and to use one-on-one marketing strategies. Wireless Internet access is rapidly gaining popularity due to its convenience and flexibility, thus it will be necessary for organizations to successfully integrate wireless communication channels in their strategic initiatives. The number of wireless web users in the U.S.A. are predicted to grow from two million in year 2000 to 89 million by year 2005, and worldwide it is expected to increase from 39 million in year 2000 to 729 million in year 2005 (Napier et al., 2003). Effective use of the Internet and wireless channels will enable organizations to obtain immediate feedback about their products/services, and allow more customers access to their product offerings. Cohesive integration of these emerging channels with traditional channels of communication will be important for attracting new customers and retaining existing customers, and for developing long-term relationships with customers to maximize their lifetime value to the organization.

\section{References}

1. Bannon, K. (2002), “Campaign Management,” B to B, 87:4, April 8, 2002, pp. 19-21.

2. $\quad$ Baron, T. (2000), "Making the Sale is Only the Beginning," Information Week, May 15, p. 92.

3. Bellman, S., Lohse, G. and Johnson, E. (1999), "Predictor of Online Buying Behavior," Communications of the ACM, 42:12, pp. 32-38.

4. Berry, M. and Linoff, G. (2000), Mastering Data Mining: The Art and Science of Customer Relationship Management, Wiley Computer Publishing, New York, NY.

5. Block, M. and Segev, A. (1996), "Leveraging Electronic Commerce for Competitive Advantage: A Business Value Framework," Proceedings of the Ninth International Conference on EDI-ISO, Bled, Slovenia.

6. Chen, L., Gillenson, M.L. and Sherrell, D.L. (2002), "Enticing Online Consumers: An Extended Technology Acceptance Perspective," Information \& Management, 39, pp. 705-719.

7. Dyche, J. (2000), "Getting and Keeping the New E-customer," Teradata White Paper.

8. Eighmey, J. (1997), "Profiling User Responses to Commercial Web Sites," Journal of Advertising Research, 37:3, pp. 59-66.

9. Feraud, G. (2000), "A Century of Information Management," Mastering Information Management, Financial Times/Prentice-Hall, London, United Kingdom. pp. 19-21. 
10. Finnie, W. and Randall R.M. (2002), "Loyalty as a Philosophy and Strategy: An Interview with Frederick F. Reichheld," Strategy \& Leadership, 30:2, pp. 25-31.

11. Gunasekaran, A., Marri, H.B., McGaughey, R.E. and Nebhwani, M.D. (2002), "E-commerce and its Impact on Operations Management," International Journal of Production Economics, 75, pp. 185-197.

12. Hall, O. P. (2001), "Mining the Store," The Journal of Business Strategy, 22:2, March/April, pp. 24-27.

13. Harreld, H., Krill, P. and Schwartz, E. (2002), "VANs Shift EDI Layer,” www.infoworld.com, July 22, pp. 31-32.

14. Hill, S. Jr. (2002), “It Ain’t Magic,” www.manufacturingsystems.com, June, pp. 30-35.

15. Keaveney, S.M. (1995), “Customer Switching Behavior in Services Industries: An Exploratory Study,” Journal of Marketing, 59, April, pp. 71-82.

16. Kotler, P. (2000), Marketing Management: Analysis, Planning, Implementation, and Control, Prentice-Hall, Englewood Cliffs, NJ.

17. Lais, S. (2002), "How to Stop Web Shopper Flight," ComputerWorld, June 17, pp. 44-45.

18. Laudon, K.C. and Laudon, J.P. (1997), Essentials of Management Information Systems - Organizations and Technology, Prentice-Hall, Englewood Cliffs, NJ.

19. Laudon, K. C. and Traver C. G. (2002), E-Commerce: Business, Technology, Society, Prentice-Hall, Englewood Cliffs, NJ.

20. Lejeune, M. (2001), "Measuring the Impact of Data Mining on Churn Management," Internet Research: Electronic Networking Applications and Policy, 11:5, pp. 375-387.

21. Lemon, K.N., White, T.B. and Winer, R.S. (2002), "Dynamic Customer Relationship Management: Incorporating Future Considerations into the Service Retention Decision," Journal of Marketing, 66, January, pp. 1-14.

22. Lin, J.C. and Lu, H. (2000), "Towards an Understanding of the Behavioural Intention to Use a Web Site," International Journal of Information Management, 20, pp. 197-208.

23. Liu, C. and Arnett, K.P. (2000), "Exploring the Factors Associated with Web Site Success in the Context of Electronic Commerce," Information \& Management, 38:1, pp. 23-33.

24. McKeown, M. (2001), E-Customer: Customers Just Got Faster and Smarter. Catch Up. Financial Times/Prentice-Hall, London, United Kingdom.

25. McIvor, R. Humphreys, G. and Huang, G. (2000), "Electronic Commerce: Re-Engineering the BuyerSupplier Interface Business Process,” Management Journal, 6:2, pp. 122-128.

26. Mena, J. (1999), Data Mining Your Web Site, Digital Press, Boston, MA.

27. Morphett, I. (1999), "Foreword," BT Technology Journal, 17:3, pp. 17-23.

28. Napier, H., Judd, P., Rivers, O. and Adams, A. (2003), E-Business Technologies, Thomson - Course Technology, Boston, MA.

29. Paulson, L. (2000), “Data Quality: A Rising E-Business Concern,” IT Pro, July/August, pp. 10-14.

30. Peppard, J. (2000), “Customer Relationship Management in Financial Services," European Management Journal, 18:3, pp. 312-327.

31. Ralston, R.W. (1996), "Model Maps Out a Sure Path to Grow in the Marketplace," Marketing News, May $20^{\text {th }}$, pp. 12.

32. Rooney, P. (2002), “XML Web Services: Brand-new Key for SMBs,” www.crn.com, July 22, pp. 38-40.

33. SAS Institute (2000), "Best Practice in Churn Prediction," SAS Institute White Paper.

34. Strauss, B., Chjnacki, K., Decker, A. and Hoffmann, F. (2001), "Retention Effects of a Customer Club," International Journal of Service Industry Management, 12:1, pp. 7-19.

35. Taylor, D. and Bregg, T. (1995), "The Business Value of Electronic Commerce", Strategic Analysis Report, R-617-121, Gartner Group, Stanford, CT.

36. Turban, E., Lee, J., King, D. and Chung, H.M. (2000), Electronic Commerce: A Managerial Perspective, Prentice-Hall, London, United Kingdom.

37. VanderAalst, W.P. (1999), "Process-Oriented Architectures for Electronic Commerce and Interorganizational Workflow," Information Systems, 24:8, pp. 639-671.

38. Violino, B. (2001), "The Search for E-Business Returns - As the Economy Sputters, Companies Must Assess How Internet Technology Will Improve the Bottom Line,” InternetWeek, October 15, pp. 9-13.

39. Wang, F., Head, M. and Archer, N. (2000), "A Relationship-Building Model for the Web Retail Marketplace," Electronic Networking and Applications, 10:4, pp. 374-384. 
40. Weinstein, A. (2001), "Customer Retention: A Usage Segmentation and Customer Value Approach," Journal of Targeting, Measurement and Analysis of Marketing, 10:3, pp. 259-268.

Notes 